\title{
Personal protective behaviour
}

\author{
Robert West ${ }^{1}$, Susan Michie ${ }^{1}$ \\ 1 University College London, University of London
}

A protective behaviour enacted by a person to protect themselves or others from a threat to their health or safety.

Synonym: PPB

Curator note: Intended to be part of a Behaviour Ontology which in turn is part of the Behaviour Change Intervention Ontology

Elaboration:This class of behaviours is distinct from thoses that are enacted to protect, for example, property or other animals. They are enacted by individuals in a personal capacity rather than on behalf of an organisation or agency.

Examples: Handwashing with soap or a hand sanitiser, using a tissue to catch droplets emitted when coughing or sneezing, not touching one's T-Zone (eyes, nose or mouth), wearing a seat belt when travelling in a vehicle, wearing safety goggles. 